\title{
Multi-scale permeability estimation for a tropical catchment
}

\author{
Nick A. Chappell, ${ }^{1 *}$ Stewart W. Franks and Jonny Larenus ${ }^{2}$ \\ ${ }^{1}$ Centre for Research on Environmental Systems and Statistics, IENS, Lancaster University, Lancaster LA1 4YQ, UK \\ ${ }^{2}$ Danum Valley Field Centre, Forestry Upstream Division, Sabah Foundation, 91112 Lahad Datu, Sabah, Malaysia
}

\begin{abstract}
:
Physically based and spatially distributed modelling of catchment hydrology involves the estimation of block or whole-hillslope permeabilities. Invariably these estimates are derived by calibration against rainfall-runoff response. Rarely are these estimates rigorously compared with parameter measurements made at the small scale. This study uses a parametrically simple model, TOPMODEL, and an uncertainty framework to derive permeability at the catchment scale. The utility of expert knowledge of the internal catchment dynamics (i.e. extent of saturated area) in constraining parameter uncertainty is demonstrated. Model-derived estimates are then compared with core-based measurements of permeability appropriately up-scaled. The observed differences between the permeability estimates derived by the two methods might be attributed to the role of intermediate scale features (natural soil pipes). An alternative method of determining block permeabilities at the intermediate or hillslope scale is described. This method uses pulse-wave tests and explicitly incorporates the resultant effects of phenomena such as soil piping and kinematic wave migration. The study aims to highlight issues associated with parameterizing or validating distributed models, rather than to provide a definitive solution. The fact that the permeability distribution within the Borneo study catchment is comparatively simple, assists the comparisons. The field data were collected in terrain covered by equatorial rainforest. Combined field measurement and modelling programmes are rare within such environments. (C) 1998 John Wiley \& Sons, Ltd.
\end{abstract}

KEY WORDS parameter uncertainty; permeability, soil piping; TOPMODEL; upscaling

\section{INTRODUCTION}

Spatial patterns in the hydraulic properties of soil or weathered rock affect the direction and magnitude of subsurface flow (e.g. Zaslavsky and Sinai, 1981; Chappell et al., 1990). These hydraulic properties include the moisture release characteristic, porosity and dispersivity, though it is the property of permeability that usually exerts the greatest control on the flow vectors. Use of catchment-scale hydrological models that incorporate spatially distributed permeability estimates is an acknowledgement of these effects. Typically, application of these models involves the use of very limited numbers of small-scale permeability measurements as initial estimates of larger scale block parameters. The parameter set of these block or hillslope-scale parameters that best predicts the river discharge hydrograph is then identified by automatic calibration (Beven, 1989; Anderson and Burt, 1990). Rigorous comparisons of field-measured permeability and that derived by catchment-scale model inversion are rarely attempted. This is probably because of uncertainties caused by: (a) limited field data, (b) the need to up-scale measurements or (c) non-uniqueness of model

\footnotetext{
* Correspondence to: Dr. N. Chappell, Institute of Environmental and Natural Sciences, Lancaster University, Lancaster, LA1 4YQ. 
parameter sets. In response, this study attempts to make such a comparison. For this comparison, a reasonably large data set of core-based permeabilities is used in a region where the spatial pattern is expected to be relatively simple. This improves the reliability of the conclusions. To improve the reliability further, the catchment-derived permeability estimates are based on the use of a parametrically simple, yet physically based model within an uncertainty framework.

Several literature reviews (e.g. Beven and Germann, 1982; Jones, 1990) demonstrate that many hillslopes contain systems of preferential channels known as macropores or natural soil pipes. Some studies indicate that flow within soil pipes can be a dominant pathway for the movement of storm rainfall to rivers, yet characterization is difficult given the complex nature of their networks. Small-scale measurements of the permeability of soil in between these discrete preferential paths may, therefore, be seen to underestimate the 'block permeability' (Wen and Gómez-Hernández, 1996) of a larger, hillslope-sized unit of soil. The catchment used for our model inversion contains active pipe systems. Return flows are observed to discharge from resurgences 0.01 and $0.5 \mathrm{~m}$ in diameter during some storm periods. As a consequence, it is expected that our model-derived permeabilities will be larger than those derived from core-scale measurements. Direct characterization of larger soil blocks as a single unit, perhaps the size of a whole hillslope, may be a way to include the effects of pipe systems (Jones, 1990; Chappell and Ternan, 1992; Bonell and Balek, 1993). Such measurement is difficult, though an attempt at this using a pulse-wave test is presented for our study area.

The study area is within a region of tropical rainforest that has been subject to some disturbance by selective, commercial logging. The localized effects of such activities on the river regime, slope instability and sediment delivery can be studied with the aid of physically based and spatially distributed modelling (e.g. Wicks and Bathurst, 1996). Such modelling requires block permeabilities representative of terrain elements smaller than the catchment unit but larger than the core-scale measurements. This study aims to develop a greater understanding of permeability estimation at this intermediate, or hillslope, scale. Such work is particularly important within tropical areas, where the rate of land conversion can be high and where there are few soil hydraulic data or modelling studies (Bonell and Balek, 1993; Bruijnzeel, 1996).

\section{RESEARCH SITE}

Multi-scale estimation of permeability was made within a $12 \mathrm{~km}^{2}$ region of haplic alisol soil close to the Danum Valley Field Centre (Pusat Luar Lembah Danum). The centre is located at $117^{\circ} 48 \cdot 75^{\prime} \mathrm{E}$ and $5^{\circ} 01^{\prime} \mathrm{N}$ on the east coast of the Malaysian state of Sabah, Borneo. The Forestry Upstream Division of the Sabah Foundation maintain the centre, with additional support from the Royal Society of London.

The climate at the Danum Valley Field Centre is equatorial with relatively little seasonality and an 11-year (1986-1996) mean rainfall of $2778( \pm \sigma 320) \mathrm{mm}$. To the west and south-east of the field centre the terrain is covered by primary rainforest. The forest type is lowland dipterocarp. The $4 \mathrm{~km}^{2}$ Sapat Kalisun catchment lies to the north-east of the centre and is comprised of forest, selectively logged during 1988 and 1989. Figure 1 shows the sampling areas for the three estimation methods. Core-scale measurements of permeability were taken over a $6 \mathrm{~km}^{2}$ region. The catchment-scale estimates used data for the 60-ha Baru catchment. The hillslope-scale pulse-wave tests were undertaken on a $60 \mathrm{~m}^{2}$ plot within the same catchment.

The research area is underlain by the Kuamut geological formation, which is a melange comprised largely of mudstones and sandstones (Leong, 1974). Soil of the FAO haplic alisol (Alh) unit dominates on this geological association (N. Chappell, unpublished data). These unstable soils were formerly classified (FAO-UNESCO, 1974) with the more stable soils of the current acrisol unit (FAO-UNESCO, 1990). Acrisol-alisol soils are the dominant soils in lowland south-east Asia (FAO-UNESCO, 1990). Stratigraphic logs from numerous soil pits and roadside exposures indicate that the solum (i.e. the A and B soil horizons) is typically $1.5 \mathrm{~m}$ deep and overlies $1.5 \mathrm{~m}$ of weathered rock (i.e. C horizon). The total depth of permeable media is, therefore, approximately $3 \mathrm{~m}$. The same logs indicate that very little catenary change in soil type is apparent within the alisol soil of the research area. The presence of such patterns would complicate up-scaling of the core-based permeability measurements (Chappell and Ternan, 1992). 


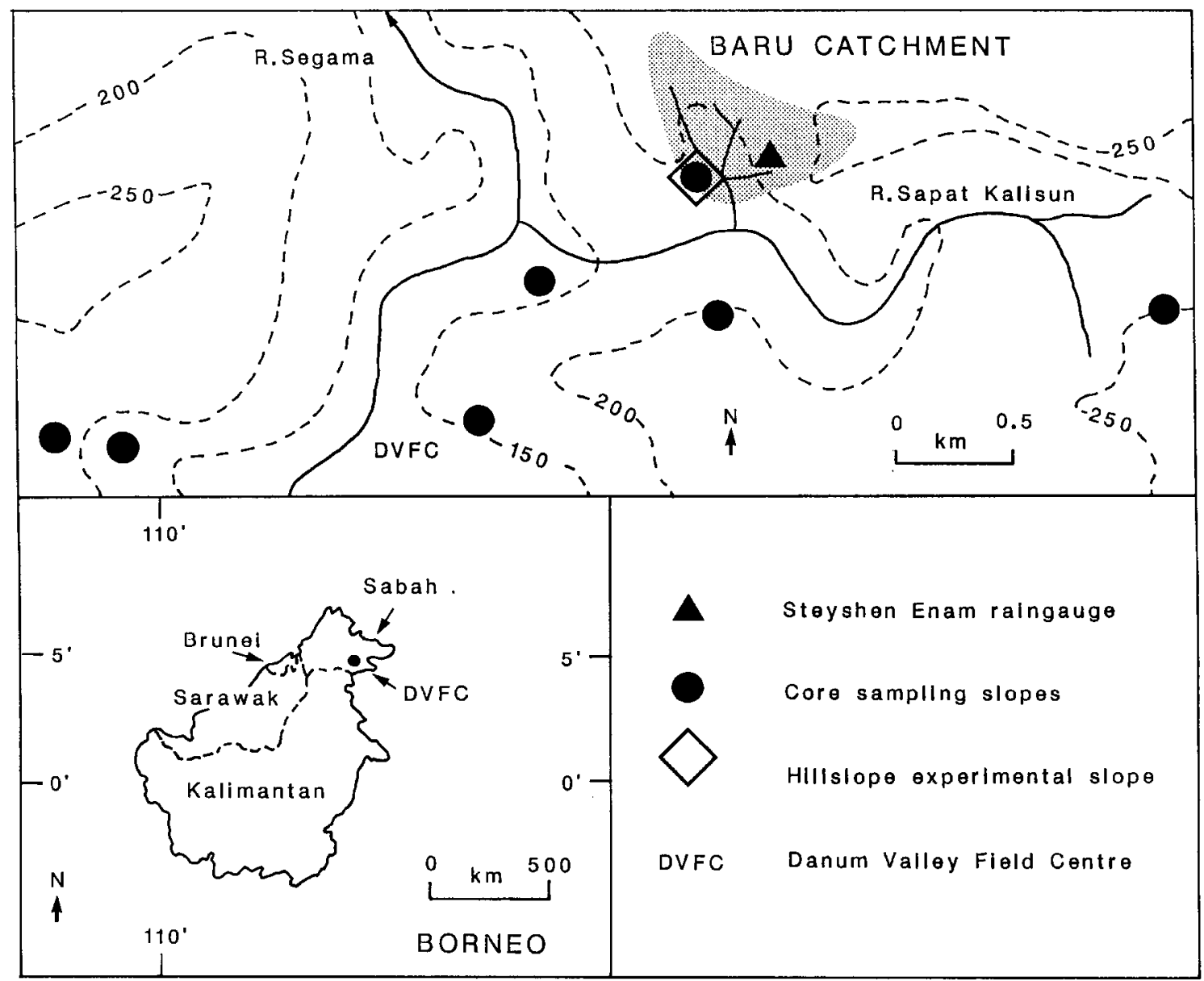

Figure 1. The $12 \mathrm{~km}^{2}$ research area (near the Danum Valley Field Centre, Ulu Segama region of Sabah, Malaysian Borneo)

The catchment-scale estimation of permeability used rainfall and river discharge data monitored in the Baru catchment over a six-month period from 6 May to 8 November 1995. Rainfall was digitally recorded at Steyshen Enam in the centre of the catchment (Figure 1). Discharge was derived from threshold-datalogged stage measurements made at a rated control section. Hourly averaged flows were derived from these data (Figure 2). The hillslope-scale tests were undertaken within a single plot that extended from the watershed divide to the second-order stream - Sungai Baru Barat within the Baru catchment (Figure 1). Further experimental details will be described within the separate sections on the core-based, catchment-based and hillslope-based approaches of permeability estimation.

\section{PERMEABILITY ESTIMATION FROM CORE-SCALE MEASUREMENT}

All core-scale measurements of permeability were undertaken with a ring permeameter (Chappell and Ternan, 1997). This method was chosen for two reasons. First, the technique is based on a direct transformation of the Darcy equation and hence is not subject to geometrical approximations in the solution. Secondly, the method was chosen because of the acknowledged reliability of the permeability estimates produced. For example, Sherlock et al. (1995) demonstrated that permeability patterns derived by this method matched the patterns of tracer migration within their tropical acrisol-alisol soil. 


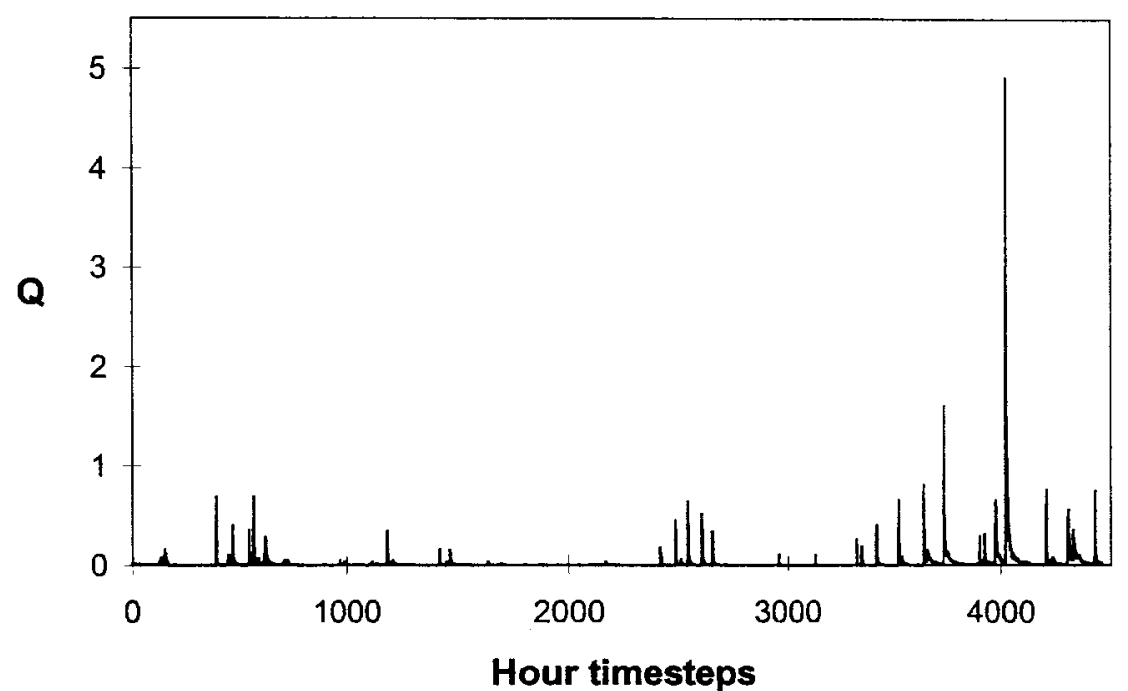

Figure 2. Six month period of river discharge used for the Baru catchment rainfall-runoff modelling. Discharge has units of $\times 10^{-6} \mathrm{~m} \mathrm{~s}^{-1}$ and the time base is in hours

A total of 70 core-based permeability measurements were taken at 26 profiles on seven slopes within the $6 \mathrm{~km}^{2}$ region (Figure 1). Cores were extracted from six depths of $0.075,0.225,0.45,0.75,1.05$ and $1.96( \pm 0.05) \mathrm{m}$ into the profiles. All testing was undertaken on $0.10 \mathrm{~m}$ long, $0.30 \mathrm{~m}$ diameter, undisturbed samples excavated from the ground and with test water at a temperature of $30 \pm 3{ }^{\circ} \mathrm{C}$. All soil samples tested were collected from profiles classified as haplic alisol. Most cores were inserted vertically into the ground, though some of the deeper samples were inserted horizontally into pit faces. Voids such as desiccation cracks or root holes were not seen to have any preferential orientation within the sampled cores, so anisotropy at the core scale was not expected.

\section{Results}

The data set of core-based permeabilities collected over the region shows a strong positive skew in the statistical distribution. Logarithmic transformation of the data produces the most symmetrical Box-andWhisker plot of the transforms applied (Figure 3; Wrinker and Hays, 1975) indicating that the underlying distribution is log-normal. These observations are confirmed with the results of Kolmogorov-Smirnov tests for normality (Wrinker and Hays, 1975) where only the logarithmic transform is statistically significant (Table I). Most catchment-scale data sets of soil permeability conform to log-normal statistical distributions (see, for example, the recent studies of Sherlock et al., 1995; Chappell and Franks, 1996). Less skew can be observed in a few data sets (e.g. Elsenbeer et al., 1992; Chappell et al., 1996). The centroid of a log-normal distribution is given by the geometric mean.

The statistical variability (i.e. coefficient of variation using the geometric mean) in the whole data set is $514 \%$. This is high compared with those values for other published permeability data sets, for example, $86-190 \%$ in the review of Warrick and Nielsen (1980) and 358\% in Chappell and Franks (1996).

The spatial (vertical) variability in the permeability is more constrained, following a simple monotonic decline with depth (Figure 4a and b). The exponential function fitted to median permeability estimates for each depth follows:

$$
K_{\mathrm{S}(\mathrm{med})}=42 \mathrm{e}^{-2 \cdot 188 D}\left(R^{2}=0 \cdot 92\right)
$$

where $K_{\mathrm{S}(\mathrm{med})}$ is the core-scale, median permeability $\left(\mathrm{m} \mathrm{s}^{-1}\right)$ at measurement depth $D(\mathrm{~m})$. The accuracy of this function is indicated by the high coefficient of determination $\left(R^{2}=0.92\right)$ and by the function lying 


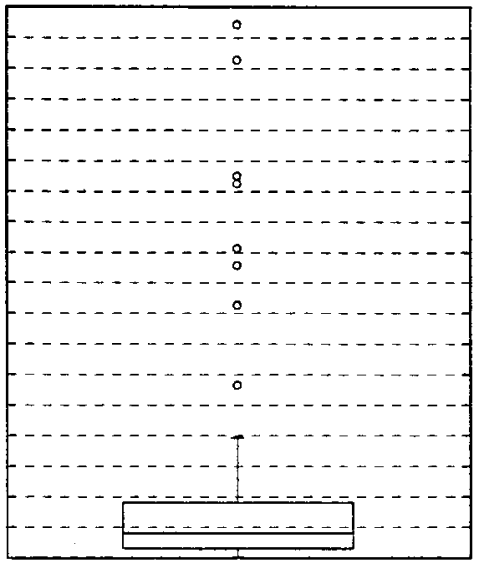

(a)

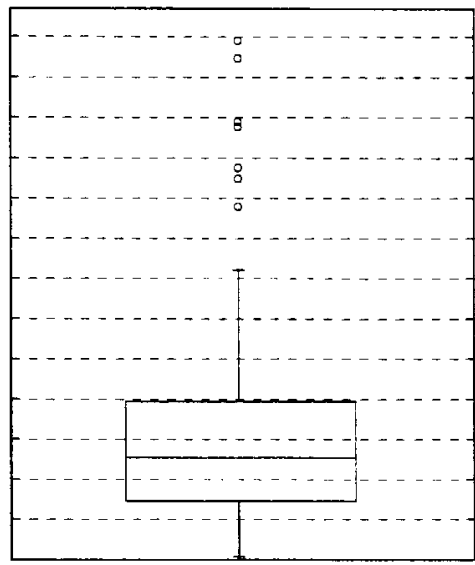

(b)

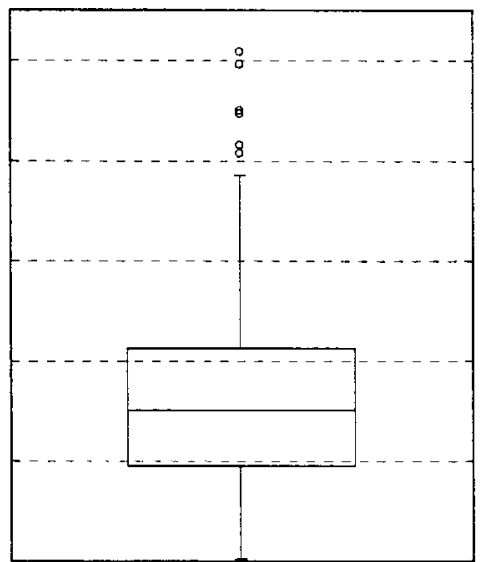

(c)

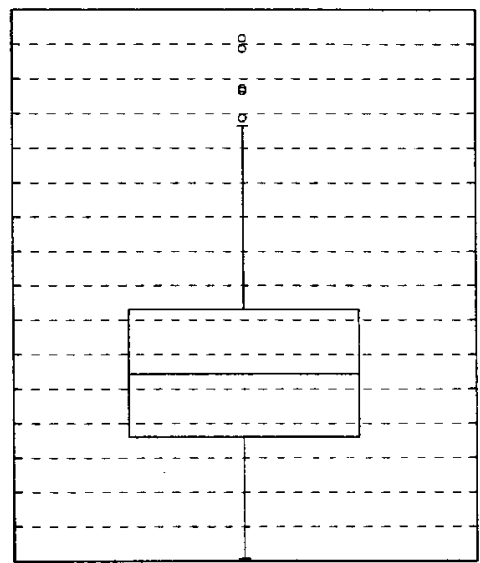

(d)

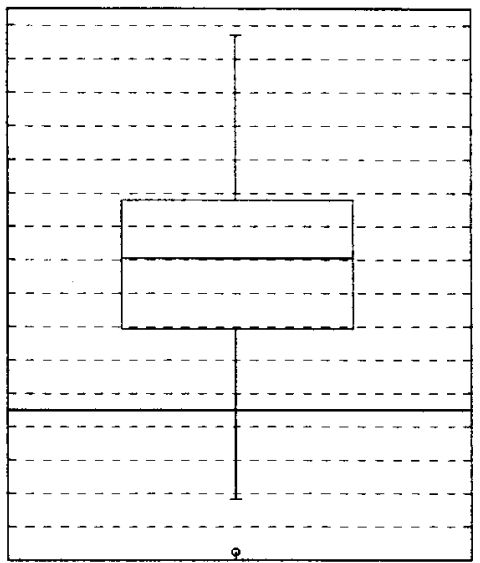

(e)

Figure 3. Box-and-Whisker plots (Wrinkler and Hays, 1975) of the statistical distribution of the core-scale permeability data. (a) Without transformation $\left(\times 10^{-6} \mathrm{~m} \mathrm{~s}^{-1}\right)$, (b) after ${ }^{2} \sqrt{ }$ transformation, (c) after ${ }^{3} \sqrt{ }$ transformation, (d) after ${ }^{4} \sqrt{ }$ transformation, and $^{2}$ (e) after $\log _{10}$ transformation

Table I. The results of Kolmogorov-Smirnov tests for 70 permeability measurements within the $6 \mathrm{~km}^{2}$ sampling area, Danum Valley. A significance level of greater than 0.95 indicates a normal distribution

\begin{tabular}{lcc}
\hline Data & $K-S$ statistic & Significance level \\
\hline Raw & $0 \cdot 3111$ & $0 \cdot 00$ \\
$2 \sqrt{ }$ transformed & $0 \cdot 1825$ & $0 \cdot 02$ \\
$3 \sqrt{ }$ transformed & $0 \cdot 1308$ & $0 \cdot 19$ \\
$4 \sqrt{ }$ transformed & $0 \cdot 1068$ & $0 \cdot 41$ \\
$\log _{10}$ transformed & $0 \cdot 0604$ & $1 \cdot 00$ \\
$-1 / x$ transformed & 0.3252 & $0 \cdot 00$ \\
\hline
\end{tabular}



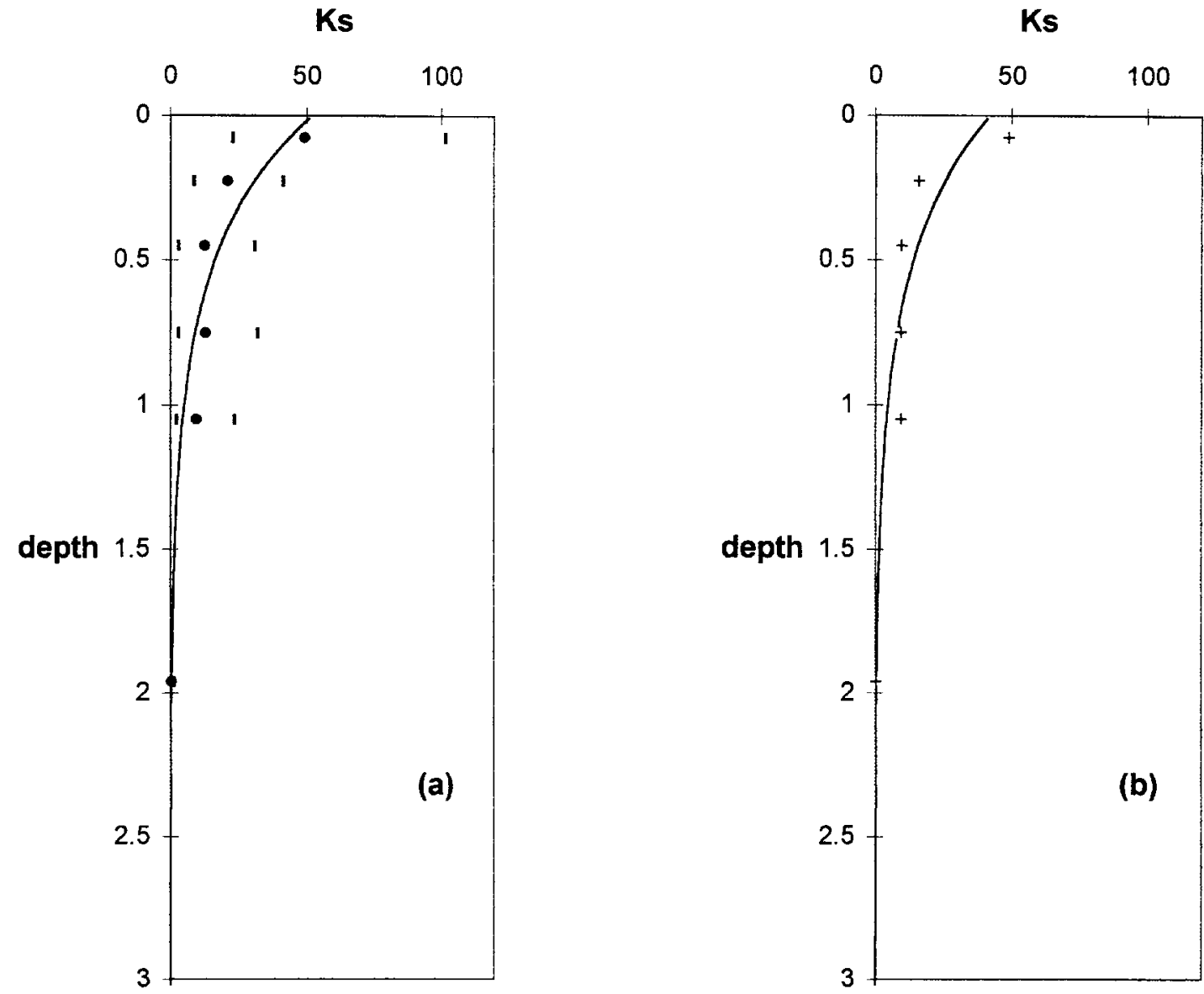

Figure 4. Vertical distribution of core-scale permeability data, with layer-specific centroid values represented by (a) the median (0), and (b) the geometric mean (+). Permeability has units of $\times 10^{-6} \mathrm{~m} \mathrm{~s}^{-1}$ and sampling depth is in metres. The bars in (a) represent the interquartile range (Wrinkler and Hays, 1975)

wholly within the interquartile range (Figure 4a). This function fits almost as well to the geometric mean permeability for each depth (Figure 4 b), i.e.

$$
K_{\mathrm{S}(\mathrm{geo})}=52 \mathrm{e}^{-2 \cdot 2907 D}\left(R^{2}=0 \cdot 88\right)
$$

where $K_{\mathrm{S}(\mathrm{geo})}$ is the core-scale, geometric mean permeability $\left(\mathrm{m} \mathrm{s}^{-1}\right)$ at measurement depth $D(\mathrm{~m})$. Using Equation (2), the geometric mean of core-scale measurements along this vertical distribution is $1.65 \times 10^{-6} \mathrm{~m} \mathrm{~s}^{-1}$.

The vertical permeability distribution is the result of the typical development of an acrisol-alisol within the humid tropics. The argillation process has resulted in reducing permeability down through the A and B horizons. Permeability reduces further from the $\mathrm{B}$ to $\mathrm{C}$ (weathered rock) to $\mathrm{R}$ (solid rock) horizon as a result of the un-interrupted in situ chemical weathering of the bedrock (Fitzpatrick, 1971). Permeability may not decline monotonically with depth where soils are developed on deposits such as head, glacio-lacustrine drift or river terrace alluvium (Chappell and Ternan, 1992). Under such conditions, estimating the lateral block permeability can be difficult. In the case of the alisol profile at Danum, however, the monotonic permeability distribution makes the averaging process comparatively simple. 

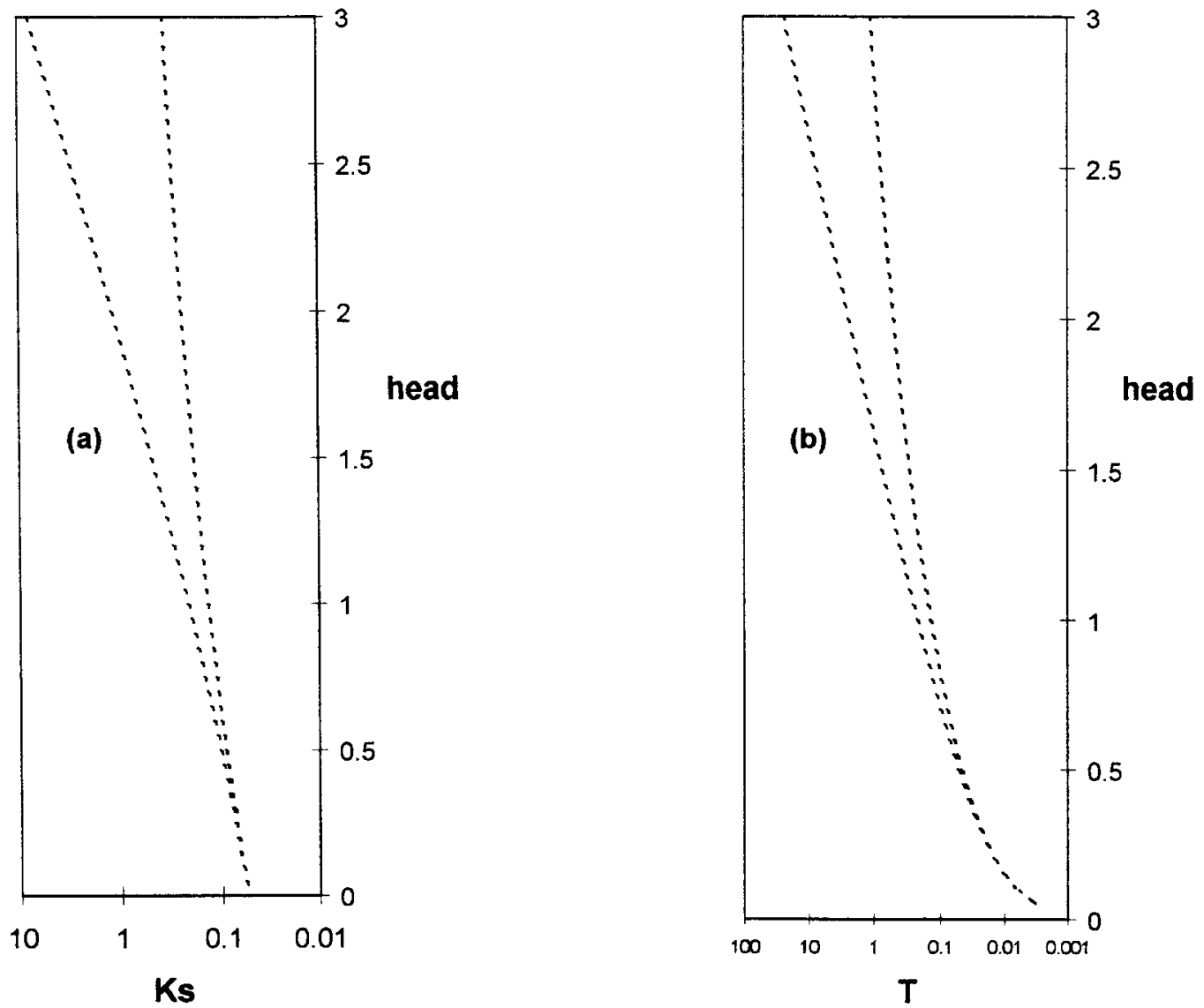

Figure 5. Lateral block permeability and transmissivity distributions derived by up-scaling core-based measurements using an harmonic mean and an arithmetic mean. (a) The lateral block permeability per saturated part of the profile $\left(K_{\mathrm{SC}}\right)$ in units of $\times 10^{-6} \mathrm{~m} \mathrm{~s} \mathrm{~s}^{-1}$, and (b) the lateral transmissivity $(T)$ in units of $\times 10^{-6} \mathrm{~m}^{2} \mathrm{~s}^{-1}$

Lateral block permeabilities are equal to an arithmetic to harmonic average of core-scale values (Cardwell and Parsons, 1945). The variation relates to the geometry of the flow pathways. It is often difficult to define $a$ priori the up-scaling method more precisely (Wen and Gómez-Hernández, 1996). Both averaging methods are, therefore, used to demonstrate uncertainty in the up-scaling. Calculated estimates of the lateral block permeability per saturated part of the profile $\left(K_{\mathrm{SC}}\right)$ are presented in Figure 5a. These estimates can be multiplied by the saturated depth to give the lateral transmissivity distribution (Figure $5 \mathrm{~b}$ ). For example, the lateral transmissivity when the ground is fully saturated $\left(T_{0}\right)$ would be $23.6 \times 10^{-6} \mathrm{~m}^{2} \mathrm{~s}^{-1}$ (Figure $5 \mathrm{~b}$ ). These data can be compared with results of the model inversion undertaken using catchment-scale data.

\section{PERMEABILITY ESTIMATION FROM CATCHMENT-SCALE INVERSION}

Catchment-scale model inversion provides a means by which lateral block permeabilties may be derived through the assessment of likely model parameterizations that reproduce a given river discharge record. However, consideration of calibration uncertainty issues is required.

As discussed by Beven (1989), many physically based models are over-parameterized in the sense that their parametric requirements are greater than can be derived through traditional model calibration techniques. Several studies have demonstrated that non-unique, near-optimal, model parameter sets (as defined by some objective function) may be met in many different areas of the parameter space (e.g. Freer et al., 1996; Franks 
et al., 1998). If model calibration is performed with the measured discharge record alone, many parameter sets may be found that reproduce this calibration variable equally well. This phenomenon indicates that parameter interactions are important in determining the behaviour of the model.

If information is collected pertaining to the internal behaviour of a catchment, then these additional data may be used to reject model parameterizations that reproduce the discharge but are not physically acceptable. Internal variables that have been used to constrain uncertainty include borehole records (Lamb, 1996) and the extent of surface saturation (Franks et al., 1997). In particular, the utility of surface saturation extent estimates was recently demonstrated in a study by Franks et al. (1998). ERS-1 synthetic airborne radar (SAR) data were employed to map the extent of surface saturation. These data were then used to constrain uncertainties in their catchment model (TOPMODEL). It was shown that the consequent reduction in terms of the feasible range of saturated transmissivity was great, even though the uncertainty in the estimates of saturated area was large. Given the utility of saturation extent estimates in constraining the feasible parameter space, a similar criterion is employed in this study.

TOPMODEL is also the model chosen for this study at Danum. The model was selected because it describes the dominant hydrological processes in physically based terms, yet requires few model parameters (Beven et al., 1995). The model is based on the premise that distributed hydrological responses are related to

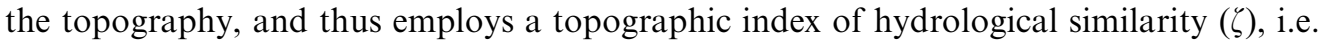

$$
\zeta=\ln \left(\frac{a}{T_{0} \tan \beta}\right)
$$

where $a$ is the upslope contributing area to a given point $\left(\mathrm{m}^{2}\right), T_{0}$ is the lateral transmissivity, when the soil and weathered rock profile is saturated to the ground surface $\left(\mathrm{m}^{2} \mathrm{~s}^{-1}\right)$, and $\tan \beta$ is the local slope angle at that point (Ambroise et al., 1996). TOPMODEL simulations produce time-series both of the river discharge $\left(Q\right.$, in $\left.\mathrm{m} \mathrm{s}^{-1}\right)$ and of the catchment-average saturation deficit $(\bar{S}$, in $\mathrm{m})$ where

$$
\bar{S}=-\frac{m}{A} \int \Sigma \zeta+\ln R(\mathrm{~d} A)
$$

and $m$ is the discharge recession parameter $(\mathrm{m}), A$ is the catchment area $\left(\mathrm{m}^{2}\right)$ and $R$ is the rainfall input $(\mathrm{m})$. This can be related to a catchment-average, water-table head using

$$
H=D-\left(\frac{\bar{S}}{\eta_{\text {eff }}}\right)
$$

where $H$ is the water-table head above the solid rock (m), $D$ is the depth to the solid rock (m) and $\eta_{\text {eff }}$ is the effective porosity. Within this study, an estimate of the effective porosity was derived from the difference between the total porosity and the moisture content at $-1.5 \mathrm{kPa}$ capillary potential (after Luxmoore, 1981; Watson and Luxmoore, 1986). Within TOPMODEL the lateral transmissivity of the saturated part of the profile, $T\left(\mathrm{~m}^{2} \mathrm{~s}^{-1}\right)$ is typically assumed to follow an exponential decline with water table depth, following

$$
T=T_{0} \mathrm{e}^{-\bar{S} / m}
$$

The lateral block permeability over the saturated part of the profile $\left(K_{\mathrm{SM}}, \mathrm{m} \mathrm{s}^{-1}\right)$ is then

$$
K_{\mathrm{SM}}=\frac{T}{H}
$$

This $K_{\mathrm{SM}}$ parameter can be compared with the parameter $K_{\mathrm{SC}}$ that is upscaled from the core-based measurements. 
Table II. Parameter ranges for the Monte Carlo sampling

\begin{tabular}{llll}
\hline Parameter & Minimum & Maximum & Units \\
\hline$T_{0}$ & $1.87 \times 10^{-6}$ & 45 & $\mathrm{~m}^{2} \mathrm{~s}^{-1}$ \\
$m$ & 0 & $7.0 \times 10^{-3}$ & $\mathrm{~m}^{-1}$ \\
$T d$ & 0 & $5.4 \times 10^{4}$ & $\mathrm{~s} \mathrm{~m}^{-1}$ \\
SRMAX & 0 & 0.6 & $\mathrm{~m}$ \\
\hline
\end{tabular}

\section{Model implementation within an uncertainty framework}

A number of recent studies (e.g. Bruneau et al., 1995; Wolock and McCabe, 1995) have shown how calibration-derived parameters (in particular $T_{0}$ ) are partly dependent on the grid resolution employed in the derivation of the topographic index. The $T_{0}$ parameter can compensate for a lack of resolution in the digital terrain model (DTM). Saulnier et al. (1997) have, however, demonstrated that the sensitivity of $T_{0}$ to the grid resolution may be reduced, if the permanent channel is removed from the derivation of the topographic index. Therefore, in this study, a fine resolution DTM (i.e. $10 \mathrm{~m}$ ) was employed and the permanent channel was removed from the calculation of the topographic index distribution.

The initial ranges in block parameters of $T_{0}, m, T d$ and $S R M A X$ (Table II) were set wider than the largest ranges used within previous TOPMODEL simulations (cf. the review of Beven et al., 1995). For example, the initial range in the critical $T_{0}$ parameter covered almost eight orders of magnitude (Table II).

Model inversion is achieved within an uncertainty framework, thus explicitly recognizing and incorporating the problem of non-uniqueness of model simulations arising from different model parameter sets. A Monte Carlo sampling strategy was adopted for the selection of contending model parameter sets. Ten thousand parameter sets were selected with random parameter values taken from uniform distributions for each parameter. The acceptability of each model parameter set for discharge prediction alone was then determined through the model efficiency measure of Nash and Sutcliffe (1970).

\section{Incorporation of expert knowledge}

Observations of the internal behaviour of the Baru catchment over several years provide a basis for further constraining the range of possible parameter sets. Visual observations of ground conditions during extreme storm events, combined with the results of runoff plot data (e.g. Sinun et al., 1992), indicate that overland flow is very limited within the Baru catchment. The spatial extent of saturated soil and the associated overland flow (during storms) is largely confined to the narrow permanent and ephemeral channels. From these observations the minimum and maximum saturated area (excluding the permanent channel) for the Baru catchment is given as 2 and $10 \%$, respectively (this range is set wider than that expected to take account of uncertainties in the estimation). TOPMODEL simulates the spatial extent of surface saturation by combining the predictions of saturation deficit $(\bar{S})$ with the topographic index distribution. Model parameter sets that produced saturated areas outside this $2-10 \%$ range were, therefore, rejected as non-behavioural.

The predicted saturation deficits were also used to derive the lateral block permeabilities [Equations (5)-(7)] using a priori-defined estimates of profile depth and effective porosity. Profile depth $(D)$ was set to the regional average of $3 \mathrm{~m}$. Moisture release characteristics have been determined for 17 cores collected from the subsoil in the west of the $12 \mathrm{~km}^{2}$ research region (M. Sherlock, personal communication). The average effective porosity $\left(\eta_{\mathrm{eff}}\right)$ from these data was $0.025 \mathrm{~m}^{3} \mathrm{~m}^{-3}$.

\section{Results}

Figure 6 shows scattergrams for the four model parameters $T_{0}, m, T d$ and $S R M A X$ plotted against the model efficiency when calibrated on discharge alone. From these plots it can be seen that reasonable fits may be achieved in many areas of the parameter space. This indicates that robust identification of individual parameter values cannot be achieved after model inversion conditioned on discharge alone. 


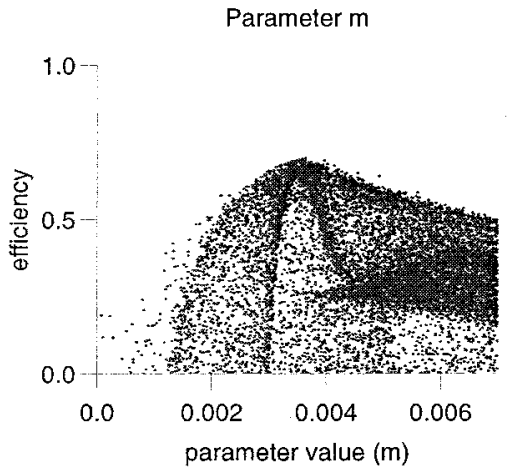

Parameter Td

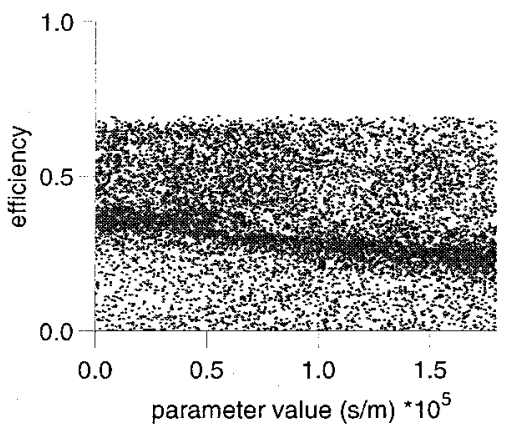

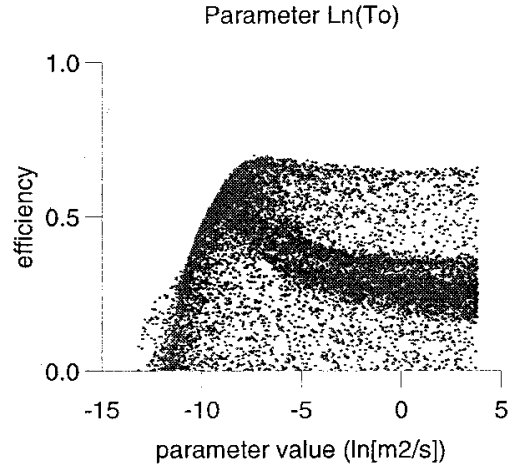

Parameter SRMAX

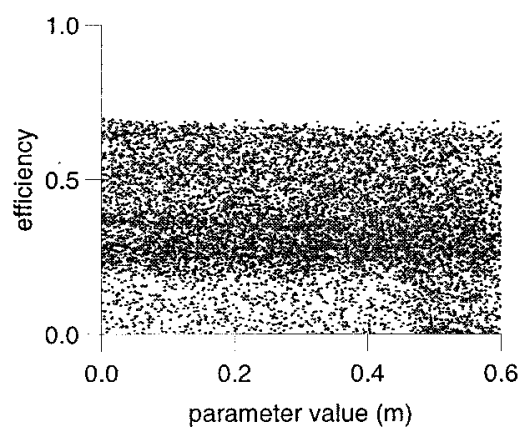

Figure 6. Scattergrams of model efficiency against (a) $m$ (metres), (b) $T_{0}\left(\ln \left[\mathrm{m}^{2} \mathrm{~s}^{-1}\right]\right)$, (c) $T d\left(\times 10^{-5} \mathrm{~s} \mathrm{~m}^{-1}\right)$, and (d) $S R M A X$ (metres) parameters after comparison with TOPMODEL discharge predictions alone

Figure 7 shows the scattergrams of the same four parameters after application of the saturated area rejection criterion. It can be seen that conditioning the model parameter sets according to the predicted extent of the saturated ground markedly affects those parameter sets that are deemed acceptable.

Figures $6 \mathrm{c}, 6 \mathrm{~d}$ and $7 \mathrm{c}, 7 \mathrm{~d}$ indicate that the Monte Carlo simulations are insensitive to the two model parameters of the unsaturated zone time delay $(T d)$ and the maximum root zone storage (SRMAX). In contrast, the response surface for the exponential recession parameter $(m)$ displays a marked optimal peak, corresponding to a value of approximately $3.5 \times 10^{-3} \mathrm{~m}$ (Figures $6 \mathrm{a}$ and $7 \mathrm{a}$ ). This value is comparable to the $m$ value of $2.6 \times 10^{-3} \mathrm{~m}$ derived independently using MRCtool of Lamb (1996). This gives some confidence that the range in $m$ may be very much constrained.

Figure $6 \mathrm{~b}$ shows the scattergram for the catchment average, lateral transmissivity when the profile is saturated to the ground surface $\left(T_{0}\right)$ against the model efficiency. From this plot it can be seen that model fits achieving high efficiencies (i.e. those greater than $0 \cdot 5$ ) occur across a large range of the parameter space. In contrast, Figure $7 \mathrm{~b}$ shows that by incorporating the saturation extent criterion, the range of values producing the best fits (above an efficiency of $0 \cdot 5$ ) is markedly constrained to the range $0 \cdot 189-4.910 \mathrm{~m}^{2} \mathrm{~s}^{-1}$.

Within this study, the transmissivity has been conditioned by the rainfall-runoff behaviour of the catchment, given the imposed physical constraints. Whilst the range of possible transmissivity remains large, high and low values of transmissivity capable of reproducing the measured discharges, but not the expected surface saturation, have been rejected. This approach contrasts with most applications of physically based catchment models, which define a priori parameter ranges with site-specific, core-scale estimates. Sets of optimal parameter values are then defined within these ranges using discharge predictions.

The minimum and maximum $T_{0}\left(0 \cdot 189\right.$ and $\left.4.910 \mathrm{~m}^{2} \mathrm{~s}^{-1}\right)$ values and the peak $m$ value $\left(3 \cdot 5 \times 10^{-3} \mathrm{~m}\right)$ are used to calculate the distribution of lateral block permeability per the saturated part of the profile $\left(K_{\mathrm{SM}}\right)$. 


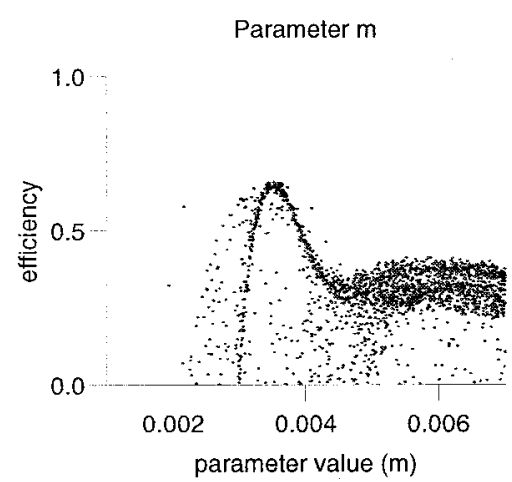

Parameter Td

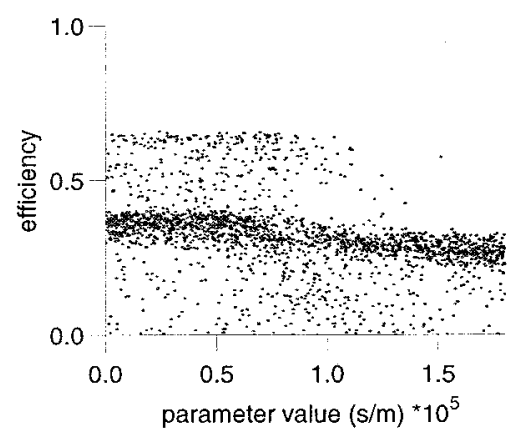

Parameter Ln(To)

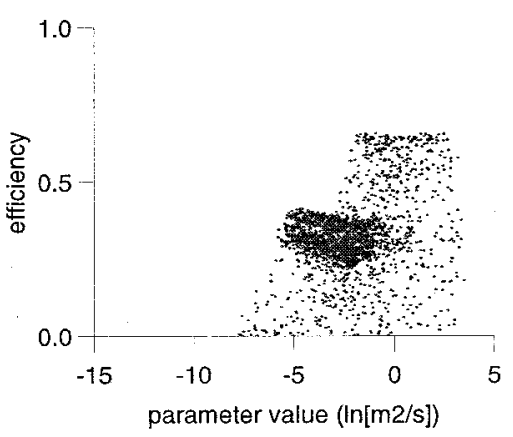

Parameter SRMAX

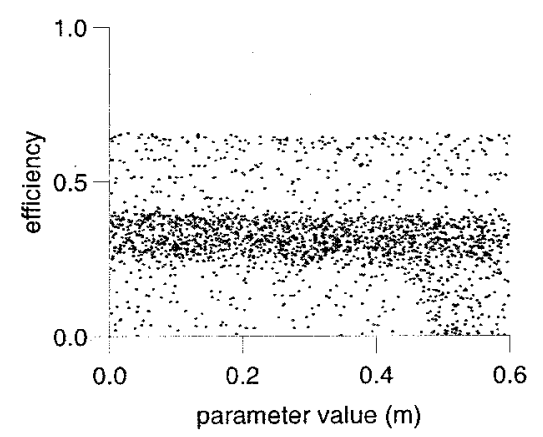

Figure 7. Scattergrams of model efficiency against (a) $m$ (metres), (b) $T_{0}\left(\ln \left[\mathrm{m}^{2} \mathrm{~s}^{-1}\right]\right)$, (c) $T d\left(\times 10^{-5} \mathrm{~s} \mathrm{~m}{ }^{-1}\right)$, and (d) $S R M A X$ (metres) parameters after comparison with discharge predictions that produce between 2 and $10 \%$ saturated area

This parameter is comparable with the core-derived $\left(K_{\mathrm{SC}}\right)$ and hillslope-derived (next section) parameters. Catchment-derived $K_{\mathrm{SM}}$ data are plotted in Figure 8 as solid lines. These data are shown for the range of catchment-average water table heads predicted for the simulation period (i.e. 1.08-2.30 m for the minimum $T_{0}$, and 0.85 to $1.88 \mathrm{~m}$ for the maximum $T_{0}$ ). Some corroboration of the effective porosity estimate $\left(0.025 \mathrm{~m}^{3} \mathrm{~m}^{-3}\right)$ is gained by observing the predicted water table (Figure 9). A level predicted to be at the base of the solum (Figure 9) is not inconsistent with borehole and tensiometer observations made across the $12 \mathrm{~km}^{2}$ Danum region (N. Chappell unpublished data). An $\eta_{\mathrm{eff}}$ estimate of, for example $0 \cdot 10 \mathrm{~m}^{3} \mathrm{~m}^{-3}$ (a factor of four larger than the estimate used), would have reduced the estimates of $K_{\mathrm{SM}}$, but raised the predicted water table to within $0.5 \mathrm{~m}$ of the ground surface. Such groundwater conditions are inconsistent with the borehole and tensiometer observations.

Those catchment-scale models that are physically-based have been developed to allow three dimensional patterns in subcatchment-scale processes to be predicted. Within the Danum research area, down-profile patterns in permeability are observed (Figure 4). At other experimental sites downslope (catenary) patterns in permeability are also observed (Chappell and Ternan, 1992). In such circumstances, it becomes difficult to up-scale core-based measurements, for subsequent comparison with rainfall-runoff-derived permeability estimates (Chappell and Ternan, 1992; Wen and Gómez-Hernández, 1996). An alternative to up-scaling block permeabilities from core-scale estimates would be to derive them directly. In the case of the hillslope, such estimates would aim to incorporate the resultant effect of down-profile and downslope permeability. Furthermore, the complex variably saturated nature of a slope (including the effects of soil pipes or macropores, kinematic and pressure waves) could be included. The hillslope is also the terrain scale that contains the 'average' water path-line along which rainfall is translated to river-flow. Hillslopes may, therefore, be 


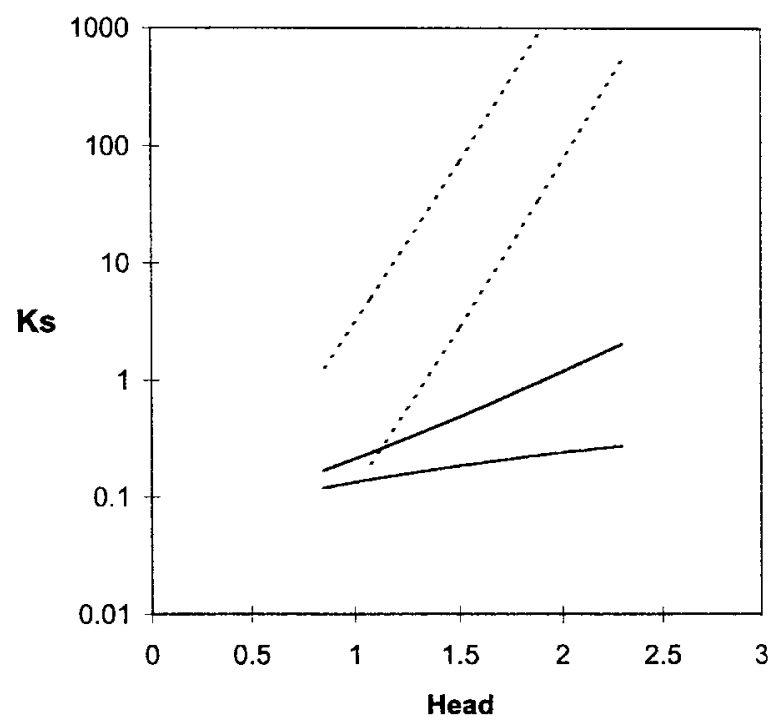

Figure 8. Lateral block permeability derived from the model inversion $\left(---, K_{\mathrm{SM}}\right)$ and that derived by up-scaling core-based measurements $\left(-, K_{\mathrm{SC}}\right)$. Lateral block permeability has units of $\times 10^{-6} \mathrm{~m} \mathrm{~s}^{-1}$ and water table head is in metres

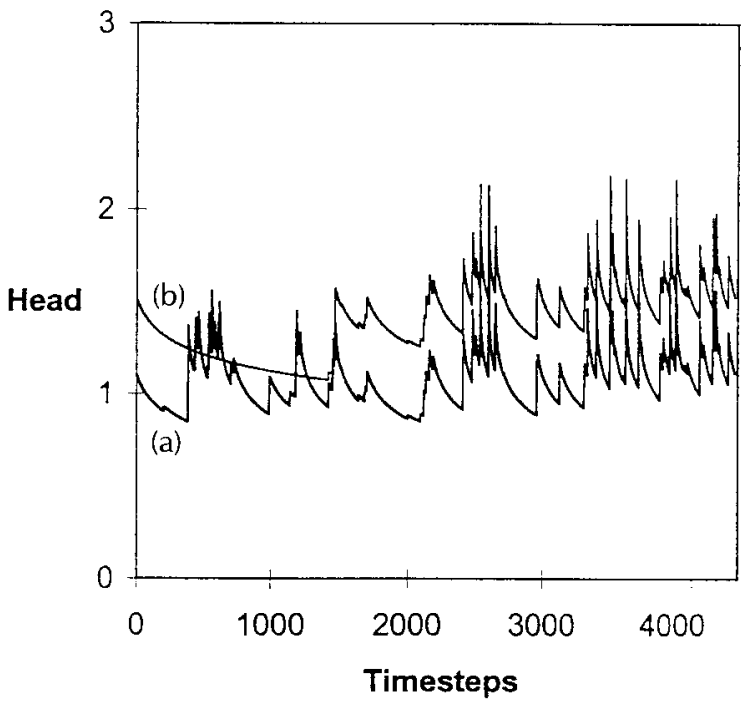

Figure 9. Average water table heads (in metres) predicted with an effective porosity of $0.025 \mathrm{~m}^{3} \mathrm{~m}^{-3}$ and (a) the maximum $T_{0}$, and (b) the minimum $T_{0}$.

seen to be the elementary unit that characterize the internal behaviour of catchments (Germann, 1990; Jones, 1990; O’Loughlin, 1990; Chappell and Ternan, 1992).

\section{PERMEABILITY ESTIMATION FROM HILLSLOPE EXPERIMENTS}

The permeability of a soil and/or weathered rock is the rate of water flow through a unit area of saturated media under a unit gradient. If the propagation rate of a water pulse through a hillslope is monitored and then corrected for the gradient (and other effects), then a very approximate estimate of the lateral block 
permeability can be obtained. A water pulse moving through several metres of soil may follow structures such as natural soil pipes. Where soil pipes are observed, lateral block permeability estimates based on hillslope-scale tests, may be more representative than those from averaged or up-scaled core-scale tests. There are two key problems with core-scale measurements. First, cores that largely comprise a soil pipe are not likely to be acceptable for permeameter tests. Secondly, the segmentation of a small pipe system into a series of discrete cores does not allow characterization of the pore continuity. Permeability is very sensitive to pore continuity (cf. Beven and Germann, 1982). In slopes where pipe flow dominates the subsurface response to rainstorms, then whole-hillslope tests, however approximate, may give better estimates of model grid-scale permeability when required for validation or parameterization of physically-based catchment modelling.

The distance between the stream and half way to the local catchment divide can be assumed to be the approximate average travel distance of rainwater migrating through the subsurface system (for shallow groundwater catchments). By applying a steady-state pulse of water to the slope at this mid-point and tracing the pulse to the stream, we can obtain a distribution of propagation velocities $(V)$ for travel to any downslope location. If we assume that the hydraulic gradient between the mid-slope and monitoring location can be approximated by the sine of the slope angle (i.e. the difference in gravitational potential over the slope distance), then lateral block permeability estimates can be derived from the propagation velocities. Given the approximations within the method and the need for parametric simplicity, we will estimate only two propagation velocities to each sampling point. The first velocity, $V_{\mathrm{S}}\left(\mathrm{m} \mathrm{s}^{-1}\right)$, is the ratio of, (a) the time from water injection to a steady-state response at a sampling location, and (b) the length of the path-line. The second velocity, $V_{\mathrm{C}}\left(\mathrm{m} \mathrm{s}^{-1}\right)$, is the ratio of, (a) the centroid time between injection and steady-state response, and (b) the length of the path-line. These values are pore water velocities, so multiplication by the effective porosity $\left(\eta_{\text {eff }}\right)$ is required to calculate the block permeabilities, which are velocities per unit area. During our pulse-wave tests, water was applied over a $1 \mathrm{~m}$ width normal to the slope. The width of the resultant plume was observed to expand with distance from the injection point. The propagation of the water needs to be corrected for this dispersion by calculation of a dispersion factor, $\tau$, which is the across-slope width of plume at the monitoring point normalized by the width at the injection site. The complete calculation of the estimate of the lateral block permeability derived from, for example, $V_{\mathrm{S}}$, is therefore

$$
K_{\mathrm{SVS}}=\frac{V_{\mathrm{S}} \eta_{\mathrm{eff}}}{\tau(\sin \beta)}
$$

where $K_{\mathrm{SVS}}$ is the lateral block permeability between the mid-slope and downslope monitoring point, as derived from $V_{\mathrm{s}}\left(\mathrm{m} \mathrm{s}^{-1}\right)$. The aim is to present a tractable solution rather than one that includes all terms (see O'Loughlin, 1990).

The experimental hillslope installed within the Baru catchment was approximately $13 \mathrm{~m}$ in length from mid-slope to the stream channel. Twelve tensiometers were installed along a central transect (Figure 10). These tensiometers were fitted with ceramic tips with a very fast response (Soil Moisture Equipment Corporation $655 \mathrm{X} 01-\mathrm{B} \cdot 5 \mathrm{M} 2$ ). The tensiometer network was supplemented with a grid of piezometers, although these are used only for definition of $\tau$ within this study. Further definition of $\tau$ was obtained by measuring the width of the return flow zone developed along the stream bank during the tests. Several pulse-wave tests were undertaken on this slope, although the results of only one test (T1KO) are presented. During experiment T1KO a petrol water pump was used to spray-irrigate an area $1 \mathrm{~m}$ by $0.5 \mathrm{~m}$ at a rate of $100-200 \mathrm{~mm} \mathrm{hr}^{-1}$. This irrigation rate did not generate infiltration excess or saturation excess overland flow outside the sprayed area. Irrigation was continued until all tensiometers had clearly reached steady state; for experiment $\mathrm{T} 1 \mathrm{KO}$ the supply was stopped after 6 hours. 


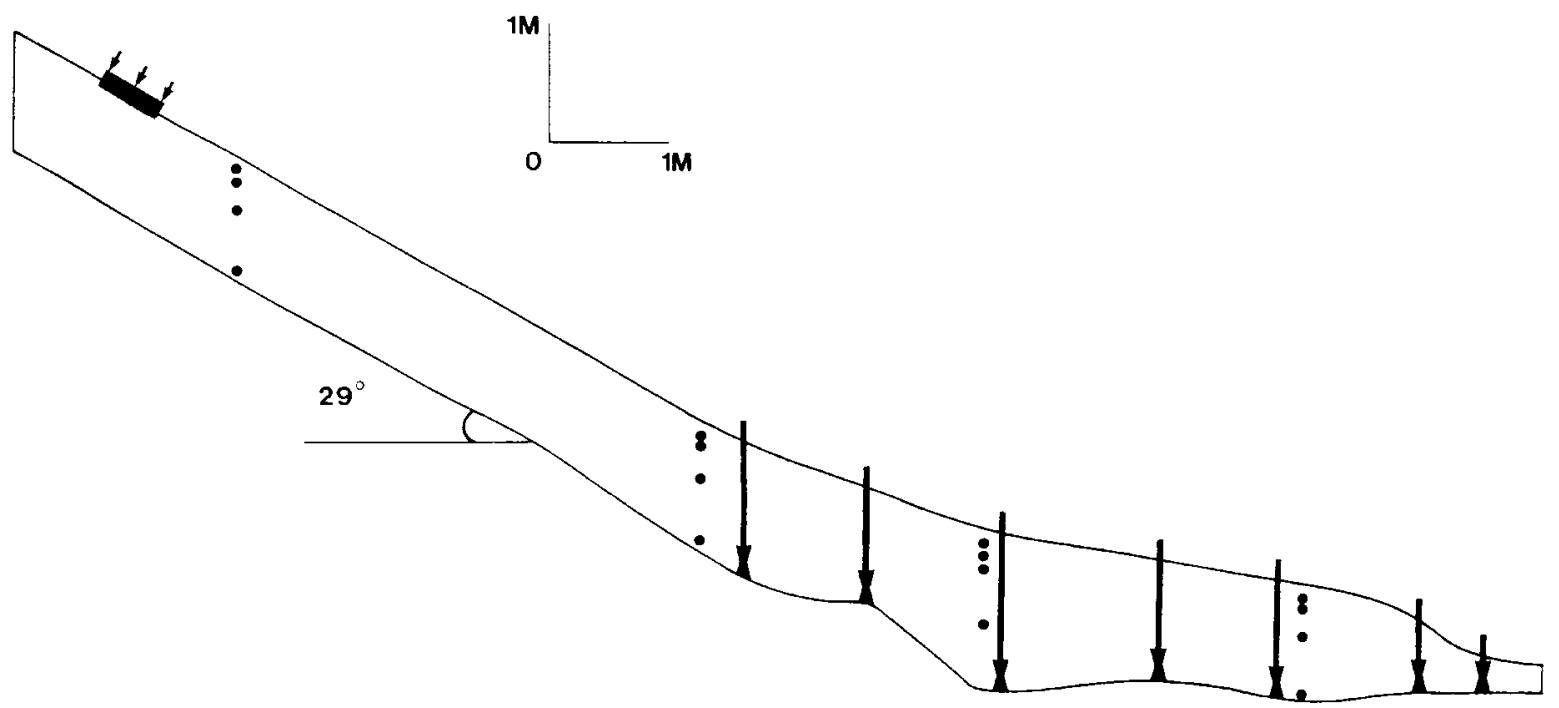

Figure 10. The distribution of tensiometer ceramics (symbol @) and piezometers (symbol :) along the central transect in the hillslope plot TR1 (Baru catchment)

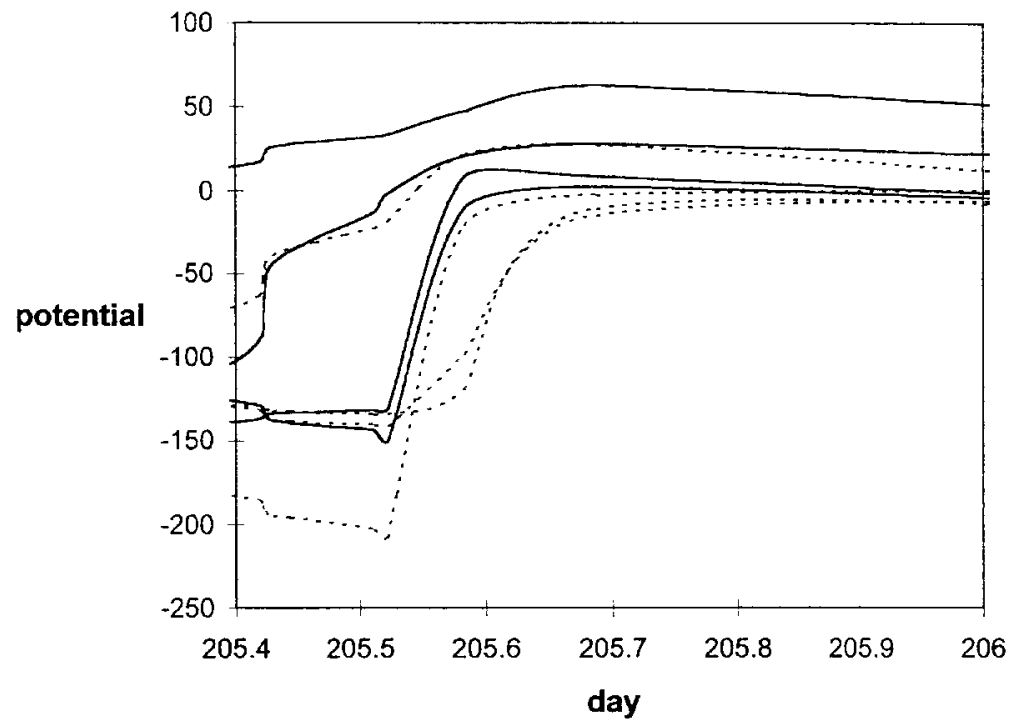

Figure 11. Tensiometer response at the near-stream array $(-)$ and next array upslope $(---)$ during experiment T1K0 (see Figure 10). Tensiometer readings are in $\times 10^{1} \mathrm{kPa}$

\section{Results}

The response of the tensiometers at the two most downslope arrays during experiment $\mathrm{T} 1 \mathrm{KO}$ is illustrated in Figure 11. Block permeabilities were calculated from the response propagation to each tensiometer during this experiment (Figure 12). The block permeabilities derived from responses close to the source appear highly uncertain. In contrast the responses at 5 to $12 \mathrm{~m}$ from the source give block permeability values that are similar for each profile and downslope location. Furthermore, the difference between the values derived from the $V_{\mathrm{S}}$ and $V_{\mathrm{C}}$ is also relatively small, the geometric mean permeability from $V_{\mathrm{S}}$ is $8.9 \times 10^{-6} \mathrm{~m} \mathrm{~s}^{-1}$ 


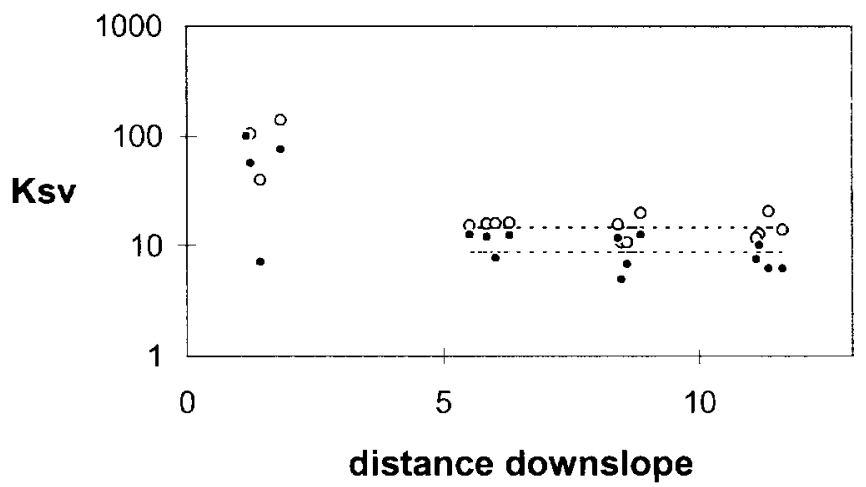

Figure 12. Lateral block permeabilities $\left(K_{\mathrm{SvS}}\right.$ and $\left.K_{\mathrm{SVC}}\right)$ derived from the hillslope pulse-wave tests $\left(\times 10^{-6} \mathrm{~m} \mathrm{~s}^{-1}\right)$. Average travel (path-line) distance is in metres.

and $14.8 \times 10^{-6} \mathrm{~m} \mathrm{~s}^{-1}$ from $V_{\mathrm{C}}$. This indicates that the identification of a representative propagation velocity is relatively robust.

\section{COMPARISON OF CORE-, HILLSLOPE- AND CATCHMENT-SCALE ESTIMATES}

Figure 8 shows the permeability estimates derived from core-based measurement and catchment-scale inversion (data are plotted over the predicted water table range). The mean water table head during the simulation period (approximated by a mean of the two traces in Figure 9) is $1.24 \mathrm{~m}$. The lateral block permeability at this mean head is between $0.527 \times 10^{-6}$ and $13.7 \times 10^{-6} \mathrm{~m} \mathrm{~s}^{-1}$ from the modelling $\left(K_{\mathrm{SM}}\right)$. The range from the up-scaled core data $\left(K_{\mathrm{SC}}\right)$ of $0.158 \times 10^{-6}-0.311 \times 10^{-6} \mathrm{~m} \mathrm{~s}^{-1}$ is clearly less than the model-derived range. Additionally, TOPMODEL assumes an exponential decline of lateral block permeability with depth, as is observed with the arithmetically up-scaled $K_{\mathrm{SC}}$ distribution. The slope of these two sets of lateral block permeability functions are, however, significantly different (Figure 8). This may indicate that there is a greater non-linearity in the catchment response than can be obtained from the core-scale measurements. These observations could be explained by the presence of active soil pipes within the catchment soils. These pipes would probably have their greatest effect on subsurface flow in very wet catchment conditions. Under such conditions the threshold for pipeflow initiation (Gilman and Newson, 1980) might be exceeded at many slope locations. Indeed, during storms where rainfall exceeded $50-100 \mathrm{~mm} \mathrm{~d}^{-1}$, natural soil pipes (0.05-0.50 m diameter) in the Baru catchment have been observed to return water to the ground surface. Soil piping may be a feature of such acrisol-alisol soils. Extensive piping has been noted in acrisolalisol soils in Sarawak, Malaysia (Baillie, 1975), Singapore (Sherlock et al., 1995) and the Amazon basin, Peru (Elsenbeer and Lack, 1996). Such a conclusion is, however, tentative given the dearth of data on piping within tropical soils (Jones, 1990).

The estimates of lateral block permeability derived from the hillslope pulse-wave experiment $\left(K_{\mathrm{SvS}}\right.$ of $8.9 \times 10^{-6} \mathrm{~m} \mathrm{~s}^{-1}$ and $K_{\mathrm{SVC}}$ of $14.8 \times 10^{-6} \mathrm{~m} \mathrm{~s}^{-1}$ ) are consistent with those derived from the model inversion (Figure 8). Furthermore, the hillslope-derived estimates are considerably larger than any of the upscaled core-based values (Figure 8). This supports the idea that the water plume applied to the experimental hillslope migrates under the influence of the soil pipes. Moreover, this may indicate that hillslope pulse-wave experiments may be a better method of either parameterizing or validating catchment-scale models.

Under conditions of relatively high water table head (i.e. the peak of large storms) the model-derived $K_{\mathrm{SM}}$ does, however, exceed the results from the hillslope experiment (i.e. $K_{\mathrm{SVS}}$ and $K_{\mathrm{SVC}}$ ). This may indicate that there are other parts of the catchment that respond much faster than the experimental hillslope. There are two possible explanations for this. First, some other slopes contain larger and hence more effective soil pipes in comparison to the study slope. Secondly, some other parts of the catchment are, on average, wetter than 
the experimental slope. At wetter locations the combined kinematic/pressure wave that results from a storm event may propagate more efficiently through the slope. Clearly, hillslope-scale experiments need to be undertaken at other locations in the Baru catchment (and at a range of antecedent conditions). A distribution of $K_{\mathrm{SVS}}$ or $K_{\mathrm{SVC}}$ could be more realistically compared with the core- or catchment-derived permeability estimates.

\section{CONCLUSIONS}

A region with a relatively simple vertical distribution of soil and weathered rock permeability has been identified. The value of using uncertain expert knowledge of catchment internal behaviour in constraining model parameter uncertainty has been demonstrated. These two observations allow some reliability to be placed on comparisons between the model- and core-derived block permeability estimates. The comparison may indicate that there is a greater non-linearity in the catchment response than can be obtained from the core-scale measurements. This could be explained by the presence of active soil pipes within the catchment soils. Approximate solutions to hillslope pulse-wave tests support the idea that soil pipes could have a significant role in the generation of river response. If these hillslope-scale tests were to be conducted at different catchment locations and antecedent moisture conditions, they might prove useful in the parameterization of spatially distributed models of catchment hydrology. The utility of hillslope- or core-derived block permeability estimates in the parameterization of catchment models is dependent on a robust estimation of the effective porosity [see Equations (5) and (8)]. A theoretically, rather than an empirically, defined effective porosity (as presented here) would clearly improve confidence in, and possibly the reliability of, this critical parameter.

\section{ACKNOWLEDGEMENTS}

The authors are indebted to Kawi Bidin, Jamal Mohd. Hanapi, Jamal Abd. Majid and Mark Sherlock for their exemplary field data collection, observations and comments. The considerable support of Dr Waidi Sinun and others of the Forestry Upstream Division, Sabah Foundation (Yayasan Sabah) is gratefully acknowledged. The Danum Valley Management Committee, the Economic Planning Unit of the Prime Minister's Department of Malaysia, the Sabah State Secretary and the Sabah Chief Minister's Department are thanked for their permission to conduct research in the Danum Valley area of Sabah, Malaysia.

This work has been undertaken as part of the Danum Valley Rainforest Research and Training Programme under project 111 with the close collaboration of Dr Waidi Sinun and Kawi Bidin (Forestry Upstream Division). The study is also a core element of a hydrology programme that forms part of the south-east Asia rainforest research programme of the Royal Society of London (reference A/175). Financial support for this work has been provided by the Royal Society of London and UK Natural Environment Research Council (grant GR3/9439).

\section{REFERENCES}

Ambroise, B., Beven, K. and Freer, J. 1996. 'Toward a generalization of the TOPMODEL concepts - topographic indexes of hydrological similarity', Wat. Resour. Res., 32, 2135-2145.

Anderson, M. G. and Burt, T. P. 1990. 'Subsurface runoff', in Anderson, M. G. \& Burt, T. P. (eds), Process Studies in Hillslope Hydrology. John Wiley and Sons, Chichester. pp. 365-400.

Baillie, I. C. 1975. 'Piping as an erosion process in the uplands of Sarawak', J. Trop. Geog., 41, 9-15.

Beven, K. J. 1989. 'Changing ideas in hydrology: the case of physically-based models', J. Hydrol., 105, 157-172.

Beven, K. and Germann, P. 1982. 'Macropores and water flow in soils', Wat. Resour. Res., 18, 1311-1325.

Beven, K. J., Lamb, R., Quinn, P. F., Romanowicz, R. and Freer, J. 1995. 'TOPMODEL', in Singh, V. P. (ed.), Computer Models of Watershed Hydrology, Water Resour. Publ., Highlands Ranch, CO. pp. 627-668.

Bonell, M. and Balek, J. 1993. 'Recent scientific developments and research needs in hydrological processes of the humid tropics', in Bonell, M., Hufschmidt, M. N. and Gladwell, J. S. (eds), Hydrology and Water Management in the Humid Tropics, Cambridge University Press, Cambridge. pp. 167-260. 
Bruijnzeel, L. A. 1996. 'Predicting the hydrological impacts of land cover transformation in the humid tropics: the need for integrated research', in Gash, J. H. C., Moore, C. A., Roberts, J. M. and Victoria, R. L. (eds), Amazonian Deforestation and Climate, John Wiley and Sons, Chichester, pp. 15-55.

Bruneau, P., Gascuel-Odoux, C., Robin, P., Merot, Ph., and Beven, K. J. 1995. 'Sensitivity to space and time resolution of a hydrological model using digital elevation data', Hydrol. Process., 9, 69-81.

Cardwell, W. T. and Parsons, R. L. 1945. 'Averaging permeability of heterogeneous oil sands', Trans. Am. Inst. Min. Metall. Pet. Eng., 160, 34-42.

Chappell, N. A. and Franks, S. W. 1996. 'Property distributions and flow structure in the Slapton Wood Catchment', Field Studies, 8, $559-5758$.

Chappell, N. A. and Ternan, J. L. 1992. 'Flow-path dimensionality and hydrologic modelling', Hydrol. Process., 6, $327-345$.

Chappell, N. A. and Ternan, L. 1997. 'Ring permeametry: design, operation and error analysis', Earth Suf. Process. Landf., 22, $1197-1205$.

Chappell, N. A, Ternan J. L., Williams, A. G. and Reynolds B. 1990. 'Preliminary analysis of water and solute movement beneath a coniferous hillslope in mid-Wales', J. Hydrol., 116, 201-215.

Chappell, N. A., Stobbs, A., Ternan, J. L. and Williams, A. 1996. 'Localised impact of Sitka spruce (Picea sitchensis (Bong.) Carr.) on soil permeability', Plant Soil, 182, 157-169.

Elsenbeer, H. and Lack, A. 1996. 'Hydrometric and hydrochemical evidence for fast flowpaths at La Cuenca, Western Amazonia', J. Hydrol., 180, 237-250.

Elsenbeer, H., Cassel, K. and Castro, J. 1992. 'Spatial analysis of soil hydraulic conductivity in a tropical rainforest catchment'. Wat. Resour. Res., 28, 3201-3214.

FAO-UNESCO, 1974. Soil Map of the World: Volume I, Legend. Unesco, Paris. p. 59.

FAO-UNESCO, 1990. Soil Map of the World: Revised Legend. FAO, Rome. p. 119.

Fitzpatrick, E. A. 1971. Pedology: A Systematic Approach to Soil Science. Oliver and Boyd, Edinburgh. p. 306.

Franks, S. W., Gineste, Ph., Beven, K. J. and Merot, Ph. 1998. 'On constraining the predictions of distributed models: the incorporation of fuzzy estimates of saturated areas into the calibration process', Wat. Resour. Res., in press.

Freer, J., Ambroise, B. and Beven, K. J. 1996. 'Baysian estimation of uncertainty in runoff production and the value of data: an application of the GLUE approach', Wat. Resour. Res., 32, 2161-2173.

Germann, P. F. 1990. 'Macropores and hydrologic hillslope processes', in Anderson, M. G. and Burt, T. P. (eds), Process Studies in Hillslope Hydrology. John Wiley and Sons, Chichester. pp. 327-363.

Gilman, K. and Newson, M. D. 1980. Soil Pipes and Pipeflow: A Hydrological Study in Upland Wales. BGRG Research Monograph, Geobooks, Norwich. p. 110.

Jones, J. A. A. 1990. 'Piping effects in humid lands', in Higgins, C. G. and Coates, D. R. (eds), Groundwater Geomorphology. Geological Society of America Special Paper 252, Boulder, Colorado. pp. 111-138.

Lamb, R. 1996. 'Distributed hydrological prediction using generalised TOPMODEL concepts', PhD Thesis, Lancaster University, Lancaster, UK.

Leong, K. M. 1974. The Geology and Mineral Resources of the Upper Segama Valley and Darvel Bay Area, Sabah, Malaysia. Memoir 4 (revised), Geological Survey of Malaysia, Kuala Lumpur.

Luxmoore, R. J. 1981. 'Micro-, meso-, macroporosity of soil', Soil. Sci. Soc. Am. J., 45, 6771

Nash, J. E. and Sutcliffe, J. V. 1970. 'River flow forecasting through conceptual models, 1: a discussion of principles', $J$ Hydrol., 10, $282-290$.

O’Loughlin, E. M. 1990. 'Perspectives on hillslope research', in Anderson, M. G. and Burt, T. P. (eds), Process Studies in Hillslope Hydrology, John Wiley and Sons, Chichester. pp. 501-516.

Saulnier, G-M., Obled, C. and Beven, K. 1997. 'Analytical compensation between DTM grid resolution and effective values of saturated hydraulic conductivity within a TOPMODEL framework', Hydrol. Process., 11, 1331-1346.

Sherlock, M. D., Chappell, N. A. and Greer, T. 1995. 'Tracer and Darcy-based identification of subsurface flow, Bukit Timah forest, Singapore', S. J. Trop. Geogr., 16, 197-215.

Sinun, W., Wong, W. M., Douglas, I. and Spencer, T. 1992. 'Throughfall, stemflow, overland flow and throughflow in the Ulu Segama rain forest, Sabah', Phil. Trans. R. Soc., London B, 355, 389-395.

Warrick, A. W. and Nielsen, D. R. 1980. 'Spatial variability of soil physical properties in the field', in Hillel, D. (ed.), Applications of Soil Physics. Academic Press, London.

Watson, K. W. and Luxmoore, R. J. 1986. 'Estimating macroporosity in a forest watershed by use of a tension infiltrometer', Soil Sci. Soc. Am. J., 50, 578-582.

Wen, X. and Gómez-Hernández, J. J. 1996. 'Upscaling hydraulic conductivities in heterogeneous media: a review', J. Hydrol., 183, 9-32.

Wicks, J. M. and Bathurst, J. C. 1996. 'SHESED — a physically-based, distributed erosion and sediment yield component for the SHE hydrological modelling system', J. Hydrol., 175, 213-238.

Wolock, D. M. and McCabe, G. J. 1995. 'Comparison of single and multiple flow direction algorithms for computing topographic parameters in TOPMODEL', Wat. Resour. Res., 31, 1315-1324.

Wrinkler, R. L. and Hays, W. L. 1975. 'Statistics: Probability, Inference and Decision, Second Edition. Holt, Rinehart and Wiston, New York. p. 889.

Zaslavsky, D. and Sinai, G. 1981. 'Surface hydrology: IV. Flow in sloping, layered soil', J. Hydraul. Div., HY1, 53-64. 